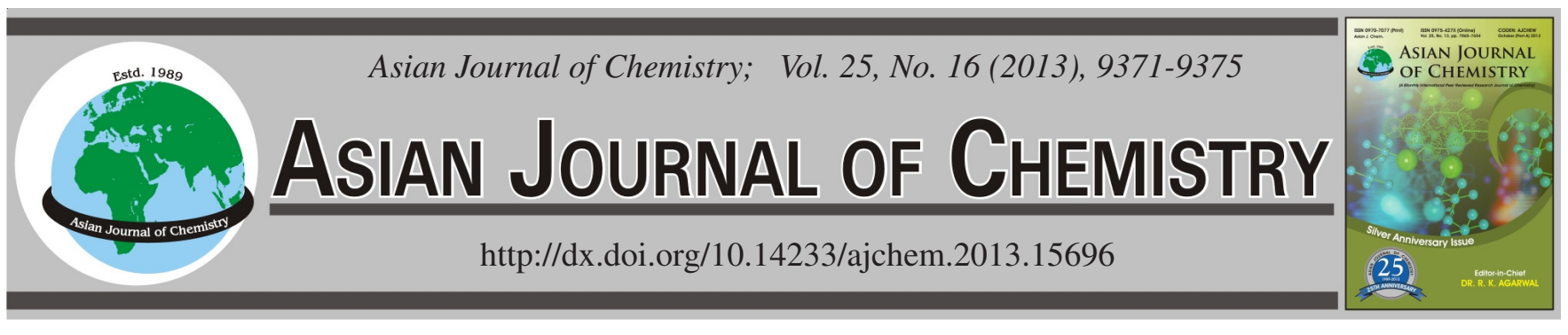

\title{
Effects of Multi Amide Compound Nucleating Agent on Non-isothermal Crystallization of Semi-aromatic Polyamide 6T/6
}

\author{
Shengchun Zhang ${ }^{1,2}$, Bing Han ${ }^{2,3}, Z_{\text {himing Feng }}^{2}$, Chunxiang Zhang ${ }^{2}$, Kejie Zhang ${ }^{2}$ and Sanjiu Ying ${ }^{1, *}$
}

\begin{abstract}
${ }^{1}$ School of Chemical Engineering, Nanjing University of Science and Technology, Nanjing 210094, P.R. China
${ }^{2}$ School of Material Engineering, Nanjing Institute of Technology, Nanjing 211167, P.R. China

${ }^{3}$ Junma Tyre Cord Company Ltd., Zhangjiagang 215617, P.R. China

*Corresponding author: Fax:+86 25 84315138; Tel: +86 25 84315549; E-mail: ying210094@ sohu.com; yingsanjiu@ sina.cn
\end{abstract}

\begin{abstract}
The influence of multi amide compound nucleating agent TMC-328 on the nonisothermal crystallization behaviour of the semi-aromatic polyamide 6T/6(PA6T/6) is investigated. It is observed that the crystallization peak temperature $\left(\mathrm{T}_{\mathrm{p}}\right)$ of PA6T/6-TMC328 is marginally higher than neat PA6T/6 at various cooling rates. Furthermore, the half-time for crystallization $\left(\mathrm{t}_{1 / 2}\right)$ decreased with in TMC-328, implying the nucleating role of TMC-328. The nonisothermal crystallization data is analyzed using Avrami and Combined Ozawa-Avrami method. The validity of kinetic models on the nonisothermal crystallization process of PA6T/6-TMC328 is described. The activation energy for nonisothermal crystallization of neat PA6T/6 and PA6T/6s with contents of TMC-328 based on Kissinger method is evaluated.
\end{abstract}

Key Words: Polyamide 6T/6, Nucleating agent, Crystallization, Non-isothermal, Kinetic.

\section{INTRODUCTION}

Semi-aromatic polyamides have been widely used in many industrial and commercial applications, by virtue of their excellent characteristics such as good thermal stability, chemical resistance, low creep and high modulus. Some of these polymers are considered as high-performance materials ${ }^{1-6}$.

Generally, the crystallization rate of semi-crystalline polymers can be enhanced by accelerating the nucleation. The additives called nucleating agents (NAs) play an important role in the acceleration of heterogeneous nucleation ${ }^{7}$. Nucleating agents can induce high crystallization temperature and degree of crystallinity $\left(\mathrm{X}_{\mathrm{c}}\right)$ of polymer in the cooling process. Thus, the addition of nucleating agents can improve the process sability, productivity in molding-injection processing, thermal properties, mechanical strengths and moduli of semicrystalline polymers. Many kinds of nucleating agents have been developed and their effects on crystallization kinetics and physical properties have been investigated for a series of semi-crystalline polymers. but it should be noted that there are no literature data about the application of nucleating agents in semi-aromatic polyamide $6 \mathrm{~T} / 6$.

TMC-328 is a multi amide compound nucleating agents product which is announced by Shanxi Institute of Chemical Industry, China (SPICI). TMC-328 is a novel efficient nucleating agents for PLA, PET, PBT and polyolefin ${ }^{8}$.
In this study, we investigated the non-isothermal crystallization behaviour of PA6T/6 by introducing nucleating agents TMC-328.

\section{EXPERIMENTAL}

The polyamide 6T/6 (PA6T/6) used in the study was prepared in our laboratory $\left(\eta=2.56\right.$ Pa.s, $\left.T_{m}=281.4{ }^{\circ} \mathrm{C}\right)$, prepared as described in reference ${ }^{9}$. TMC-328 was supplied by SPICI with melting point over $350{ }^{\circ} \mathrm{C}$.

All materials were dried in an oven at $100{ }^{\circ} \mathrm{C}$ for $12 \mathrm{~h}$. The PA6T/6 composites containing different TMC-328 nucleating agent contents (from 0-5\%) were prepared via a melt compounding method using an torque rheometer RM-200A with a screw speed of $50 \mathrm{rpm}$. In this process, the temperature profile was $300{ }^{\circ} \mathrm{C}$ and the blending time was $8 \mathrm{~min}$.

Thermal analysis was performed in a DSC 200 F3 (NETZSCH, German) differential scanning calorimeter. The instrument was calibrated using high purity indium and zinc standards. For isothermal crystallization, the samples were melted at $320{ }^{\circ} \mathrm{C}$ for 3 min to eliminate the previous thermal history and then were cooled at a constant rate to $50^{\circ} \mathrm{C}$. The preset cooling rates were $5,10,15,20$ and $30^{\circ} \mathrm{C} / \mathrm{min}$, respectively.

\section{RESULTS AND DISCUSSION}

Non-isothermal melt crystallization behaviours: The effects of multi amide compound nucleobase on the melt 
crystallization of PA6T/6 were investigated by DSC analysis. Fig. 1 shows the DSC curves of non-isothermal melt-crystallization for the neat PA6T/6 and PA6T/6 composites containing different TMC-328 nucleating agent contents. The non-isothermal crystallization parameters such as the onset temperature of crystallization $\left(\mathrm{T}_{\mathrm{o}}\right)$, the end temperature of crystallization $\left(\mathrm{T}_{\mathrm{c}}\right)$ and the exothermic peak temperature of crystallization $\left(\mathrm{T}_{\mathrm{p}}\right)$ are determined from these curves and the results are shown in Table-1.

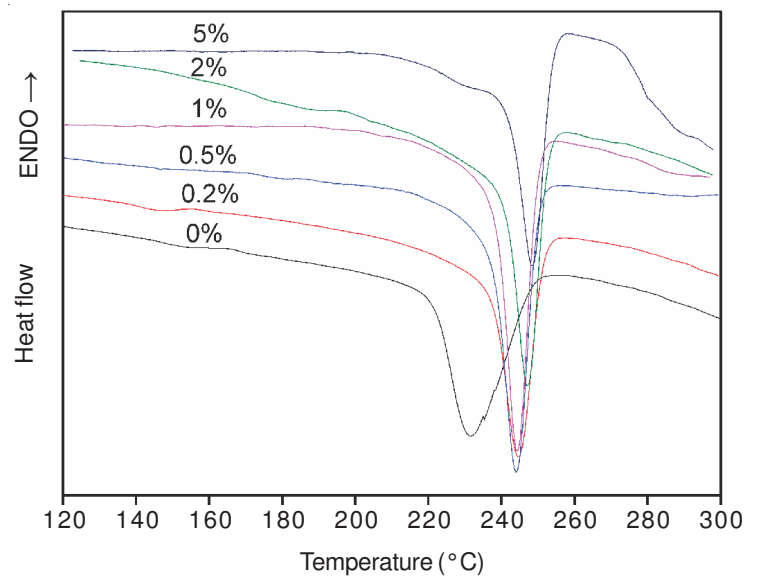

Fig. 1. DSC cooling curves of neat PA6T/6 and PA6T/6 composites at a cooling rate of $10^{\circ} \mathrm{C} / \mathrm{min}$

It is found that the introduction of TMC-328 in PA6T/6 leads to a signicant increase in $\mathrm{T}_{\mathrm{o}}, \mathrm{T}_{\mathrm{c}}$ and $\mathrm{T}_{\mathrm{p}}$. For example, at the cooling rate of $10^{\circ} \mathrm{C} / \mathrm{min}$, crystallization peak temperature for neat PA6T/6 is $231.6^{\circ} \mathrm{C}$, while for PA6T/6 composites containing $0.2 \mathrm{wt} \% \mathrm{TMC}-328$, it is $244.7^{\circ} \mathrm{C}$. This implies that the TMC-328 acts as efficient nucleating agent to increasing the rate of crystallization of PA6T/6.

Non-isothermal crystallization kinetics: Fig. 2 shows typical DSC curves of heat flow as a function of temperature at different cooling rates for neat PA6T/6 and PA6T/6-0.2 wt \% TMC-328. The non-isothermal crystallization parameters $\mathrm{T}_{\mathrm{o}}$, $\mathrm{T}_{\mathrm{c}}$ and $\mathrm{T}_{\mathrm{p}}$ have been determined from these curves and the results have been shown in Table-2. It is clear that as the rate of cooling increases, all the parameters namely $T_{o}, T_{c}$ and $T_{p}$ shift to lower temperatures.

The relative degree of crystallinity $\mathrm{X}_{\mathrm{t}}$ is required for the analysis of crystallization kinetics and the $\mathrm{X}_{\mathrm{t}}$ as a function of temperature is defined as:

$$
X_{t}=\frac{\int_{T_{0}}^{T}(d H / d T) d T}{\int_{T_{0}}^{T_{\infty}}(d H / d T) d T}
$$
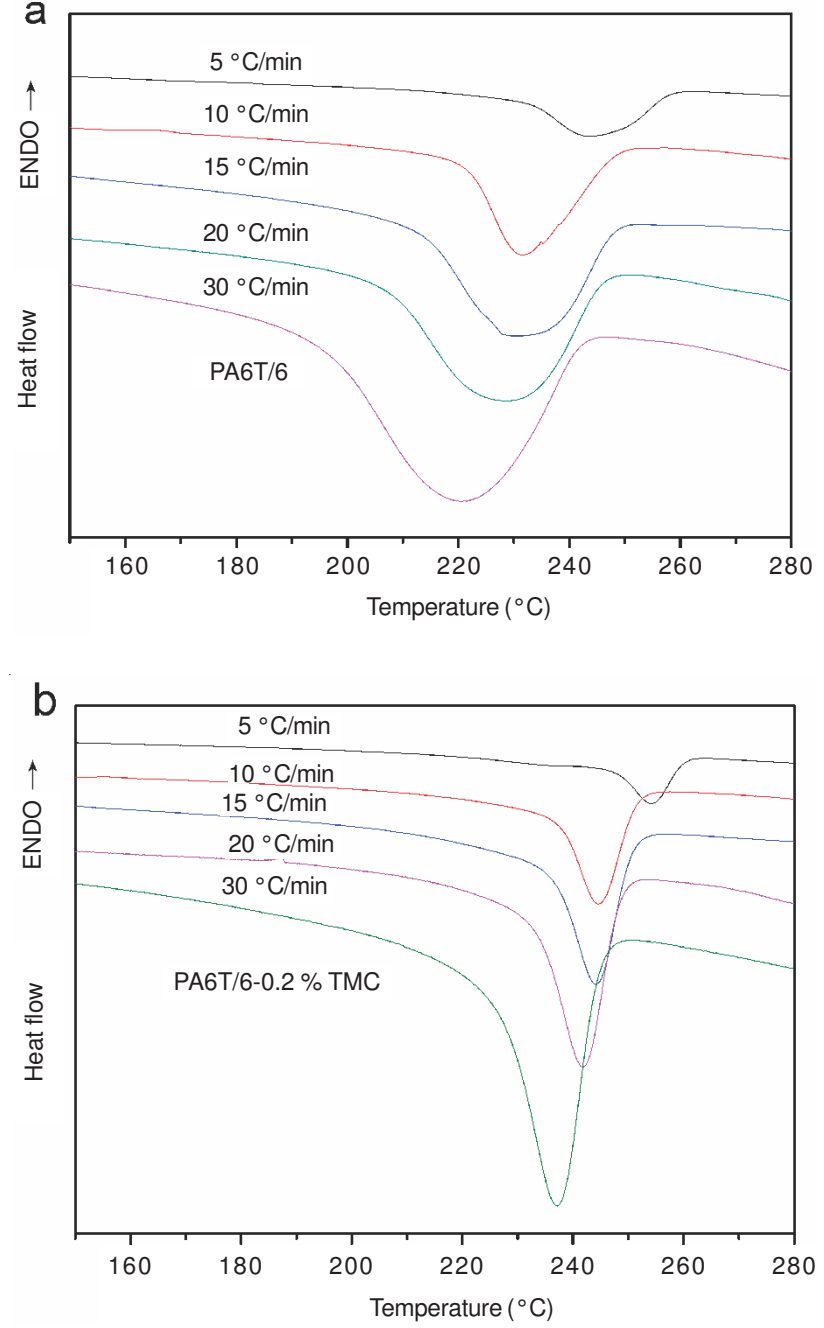

Fig. 2. DSC curves of PA6T/6 (a) and PA6T/6-TMC (0.2 wt \%) composites (b)

\begin{tabular}{cccccc}
\multicolumn{6}{c}{ TABLE-2 } \\
\multicolumn{5}{c}{$\begin{array}{c}\text { NONISOTHERMAL CRYSTALLIZATION KINETIC } \\
\text { DATA OF PA6T/6 AND NUCLEATED PA6T/6 }\end{array}$} \\
\hline \multirow{2}{*}{ Samples } & $\begin{array}{c}\Phi\left({ }^{\circ} \mathrm{C}\right) \\
\mathrm{min}^{-1}\end{array}$ & $\mathrm{n}$ & $\mathrm{Z}_{\mathrm{c}}$ & $\begin{array}{c}\mathrm{t}_{1 / 2} \\
(\mathrm{~min})\end{array}$ & $\begin{array}{c}\mathrm{Tp} \\
\left({ }^{\circ} \mathrm{C}\right)\end{array}$ \\
& 5 & 2.3 & 0.52 & 3.33 & 243.8 \\
& 10 & 2.5 & 0.84 & 1.98 & 231.6 \\
PA6T/6 & 15 & 2.2 & 0.94 & 1.31 & 230.5 \\
& 20 & 2.0 & 0.97 & 1.03 & 228.7 \\
& 30 & 2.0 & 1.00 & 0.79 & 220.7 \\
\hline \multirow{3}{*}{ PA6T/6- } & 5 & 2.7 & 0.63 & 1.99 & 254.2 \\
0.2wt\% & 10 & 3.4 & 0.90 & 1.19 & 244.7 \\
TMC & 15 & 3.3 & 1.00 & 0.86 & 244.1 \\
& 20 & 3.4 & 1.04 & 0.66 & 241.9 \\
& 30 & 3.3 & 1.06 & 0.51 & 237.3 \\
\hline
\end{tabular}

\begin{tabular}{lccccc} 
& \multicolumn{5}{c}{ TABLE-1 } \\
& \multicolumn{5}{c}{$\begin{array}{l}\text { THERMAL PARAMETERS OF PA6T/6 AND PA6T/6 COMPOSITES ATTAINED } \\
\text { IN NONISOTHERMAL MELT-CRYSTALLIZATION PROCESSES }\end{array}$} \\
\hline \multicolumn{1}{c}{ Sample } & $\mathrm{T}_{\mathrm{p}}\left({ }^{\circ} \mathrm{C}\right)$ & $\mathrm{T}_{\mathrm{o}}\left({ }^{\circ} \mathrm{C}\right)$ & $\mathrm{T}_{\mathrm{c}}\left({ }^{\circ} \mathrm{C}\right)$ & $\Delta \mathrm{T}_{\mathrm{c}}\left({ }^{\circ} \mathrm{C}\right)$ & $\left.\Delta \mathrm{H}^{(\mathrm{J} \mathrm{g}}{ }^{-1}\right)$ \\
\hline PA6T/6 & 231.6 & 247.6 & 222.9 & 18.5 & 23.56 \\
PA6T/6 TMC $(0.2 \%)$ & 244.7 & 251.1 & 237.7 & 10.8 & 24.84 \\
PA6T/6 TMC $(0.5 \%)$ & 243.9 & 249.7 & 237.7 & 9.4 & 27.79 \\
PA6T/6 TMC $(1 \%)$ & 244.3 & 249.7 & 238.5 & 8.6 & 28.19 \\
PA6T/6 TMC $(2 \%)$ & 247.1 & 252.5 & 241.3 & 9.2 & 25.42 \\
PA6T/6 TMC $(5 \%)$ & 248.4 & 253.8 & 242.8 & 9.8 & 23.97 \\
\hline
\end{tabular}


where $\mathrm{T}_{0}$ and $\mathrm{T}_{\infty}$ are the onset and end temperatures of crystallization, respectively and $\mathrm{H}$ is the enthalpy of crystallization. Using the following equation, $\mathrm{t}=\left(\mathrm{T}_{0}-\mathrm{T}\right) / \varphi$ (where $\mathrm{T}$ is the temperature at crystallization time $t$ and $\varphi$ is the cooling rate), the abscissa of temperature could be transformed into a timescale. Fig. 3 shows the relative degree of crystallinity, $X_{t}$, as a function of crystallization temperature $\mathrm{T}$ and crystallization time $\mathrm{t}$ for PA6T/6 and PA6T/6-0.2 wt \% TMC-328 at various cooling rates. The higher the cooling rate is, the shorter the crystallization time span is. The half time of non-isothermal crystallization $\left(\mathrm{t}_{1 / 2}\right)$, which is defined as the time taken the crystallinity of the sample reaches the value of $50 \%$ of the relative crystallinity, was estimated from the Xc-t curves (Fig. 3). The results are listed in Table-2.

Avrami analysis of non-isothermal crystallization: The modified Avrami equation is widely used to describe the polymer non-isothermal crystallization ${ }^{10}$.

$$
1-\mathrm{X}_{\mathrm{t}}=\exp \left(-\mathrm{Z}_{\mathrm{t}} \mathrm{t}^{\mathrm{n}}\right)
$$

where, $\mathrm{X}_{\mathrm{t}}$ is the relative crystallinity at the crystallization time t. The ' $n$ ' is Avrami exponent, which is a mechanism constant depending on type of nucleation and growth process. According to original assumptions of the theory, the value of the Avrami exponent ' $n$ ' should be an integer ranging from 1-4. The $\mathrm{Z}_{\mathrm{t}}$ is the Avrami rate constant for crystallization involving
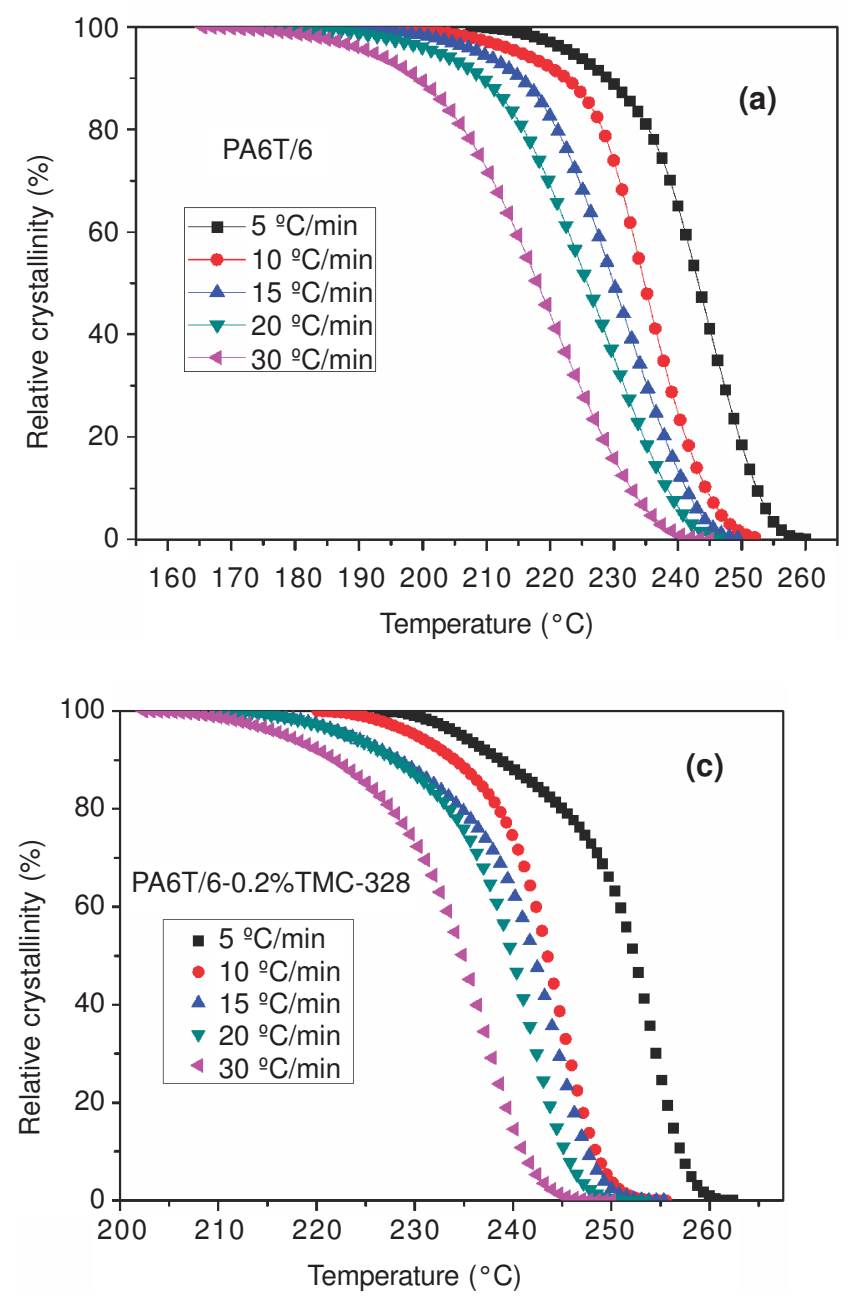

nucleation and growth parameters. The double logarithm of the eqn. 2 gives the following relation:

$$
\ln \left[\ln \left(1-X_{t}\right)\right]=\ln Z_{t}+n \ln t
$$

Since the process is non-isothermal, Jeziorny ${ }^{11}$ suggested that the rate parameter $Z_{t}$ should be corrected for the influence of cooling rate $\Phi$ of the polymer. Assuming to be constant or approximately constant, the final form of the parameter characterizing the kinetics of non-isothermal crystallization was given as follows:

$$
\log Z_{\mathrm{c}}=\frac{\log \mathrm{Z}_{\mathrm{t}}}{\Phi}
$$

Fig. 4 presents the plot of $\ln \left[-\ln \left(1-\mathrm{X}_{\mathrm{t}}\right)\right]$ versus $\ln \mathrm{t}$ of neat PA6T/6 and PA6T/6-0.2 wt \% TMC-328 with preferable linear relation. The values of $n$ and $Z_{t}$ can be obtained by the fitting of the linear slopes and the intercepts of the lines, respectively. The rate constant of crystallization, $Z_{c}$, can be obtained by eqn. 4. The values of $n$ and $Z_{c}$ are listed in Table-2.

The values of Avrami exponent 'n' for PA6T/6 and PA6T/ 6-0.2 wt \% TMC-328 range from 2.0-2.5 and 2.7-3.4, respectively. From the data it is clear that the values of $\mathrm{n}$ for PA6T/60.2 wt \% TMC-328 are all higher than PA6T/6. which implies that presence of TMC-328 in PA6T/6 drastically modied the crystallization mechanism of composites. This may be due to the predominant nucleation activity of the TMC-328 molecules in PA6T/6.
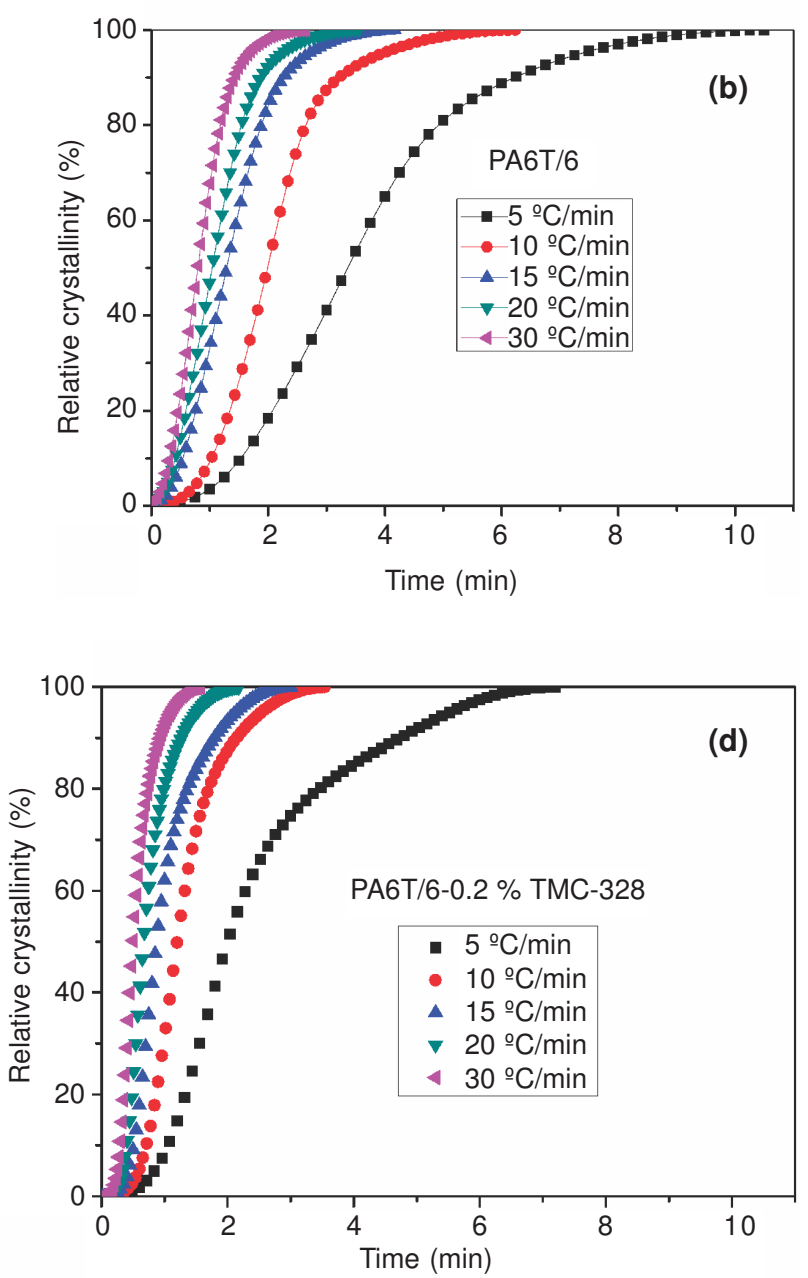

Fig. 3. Plots of $\mathrm{X}_{\mathrm{t}}$ versus $\mathrm{T}$ or $\mathrm{t}$ for crystallization of samples at different cooling rates 

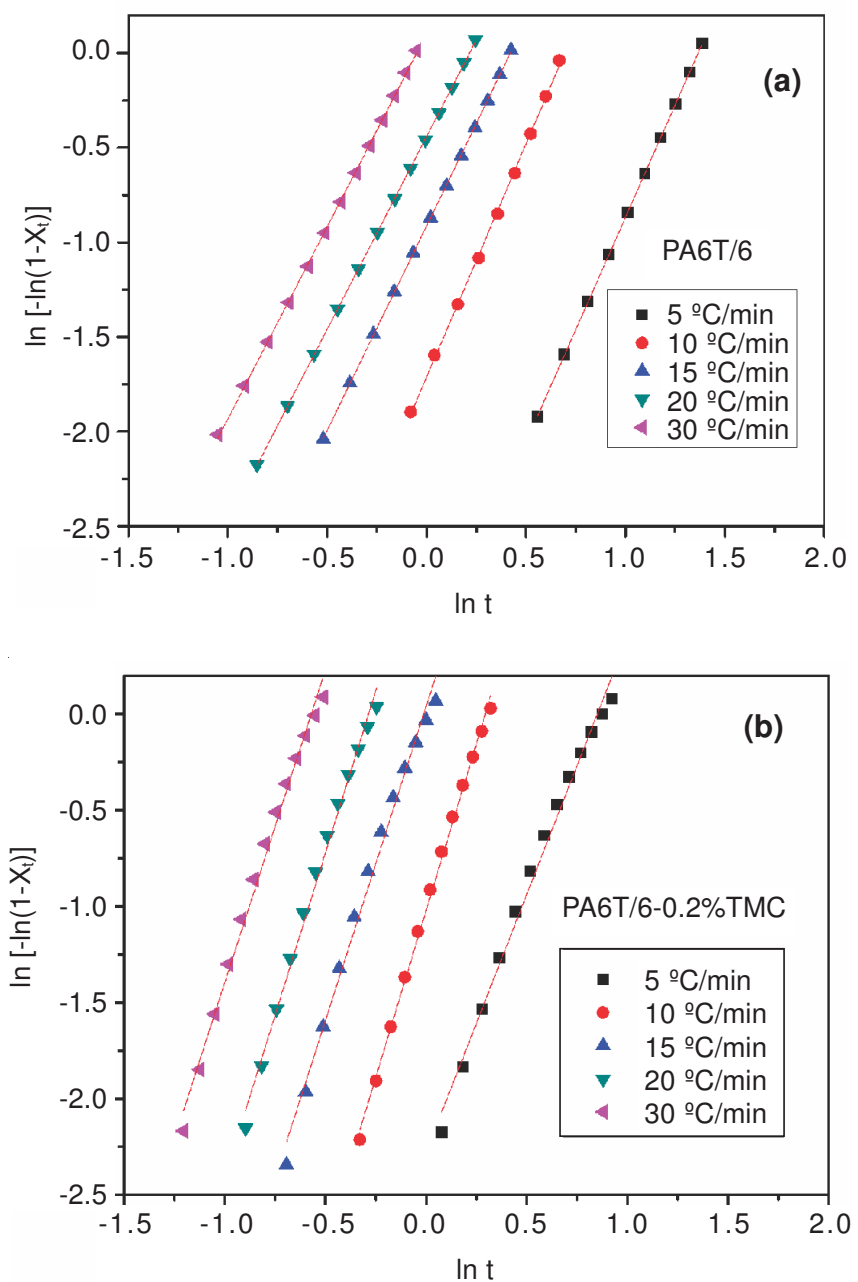

Fig. 4. Plot of $\ln \left[-\ln \left(1-\mathrm{X}_{\mathrm{t}}\right)\right]$ versus $\operatorname{lnt}$ for non-isothermal crystallization of neat PA6T/6 (a) and PA6T/6-0.2 wt \% TMC-328 (b)

Table- 2 showed that the crystallization peak temperature $T_{p}$ and the value of $t_{1 / 2}$ decreases and the $Z_{c}$ increases with increasing the cooling rate for all the samples. The lower $t_{1 / 2}$ and higher $\mathrm{Z}_{\mathrm{c}}$ for PA6T/6 filled with TMC-328 are attributed to the presence of the heterogeneous nucleation of TMC-328. The $t_{1 / 2}$ is lower and the $T_{p}$ and $Z_{c}$ are higher for nucleated PA6T/6 compared to that of pure PA6T/6 under the same cooling rate. It means that the crystallization rate of PA6T/6 nucleated with TMC-328 nucleating agent is higher than that of PA6T/6.

Combined Ozawa-Avrami approach: The Mo method is the combination of Avrami and Ozawa equations ${ }^{12}$ and the simplified formula is:

$$
\log \phi=\log \mathrm{F}(\mathrm{T})-\alpha \log \mathrm{t}
$$

where $F(T)$ refers to the value of the cooling rate chosen at a unit crystallization time at which the system has a certain degree of crystallinity. According to eqn. 5, straight lines with intercept of $\log \mathrm{F}(\mathrm{T})$ and slope $\alpha$ can be obtained by plotting $\log \phi$ versus $\log \mathrm{t}$ (Fig. 5). Data of $\log \mathrm{F}(\mathrm{T})$ are collected in Table-3. It can be seen that the value increases with increase in relative crystallinity for all polymers studied. It indicated that a higher cooling rate should be required to obtain a higher relative crystallinity in the same crystallization time. At a given relative crystallinity, the value of of PA6T/6 nucleated with TMC-328 is lower than that of PA6T/6. Such results are similar
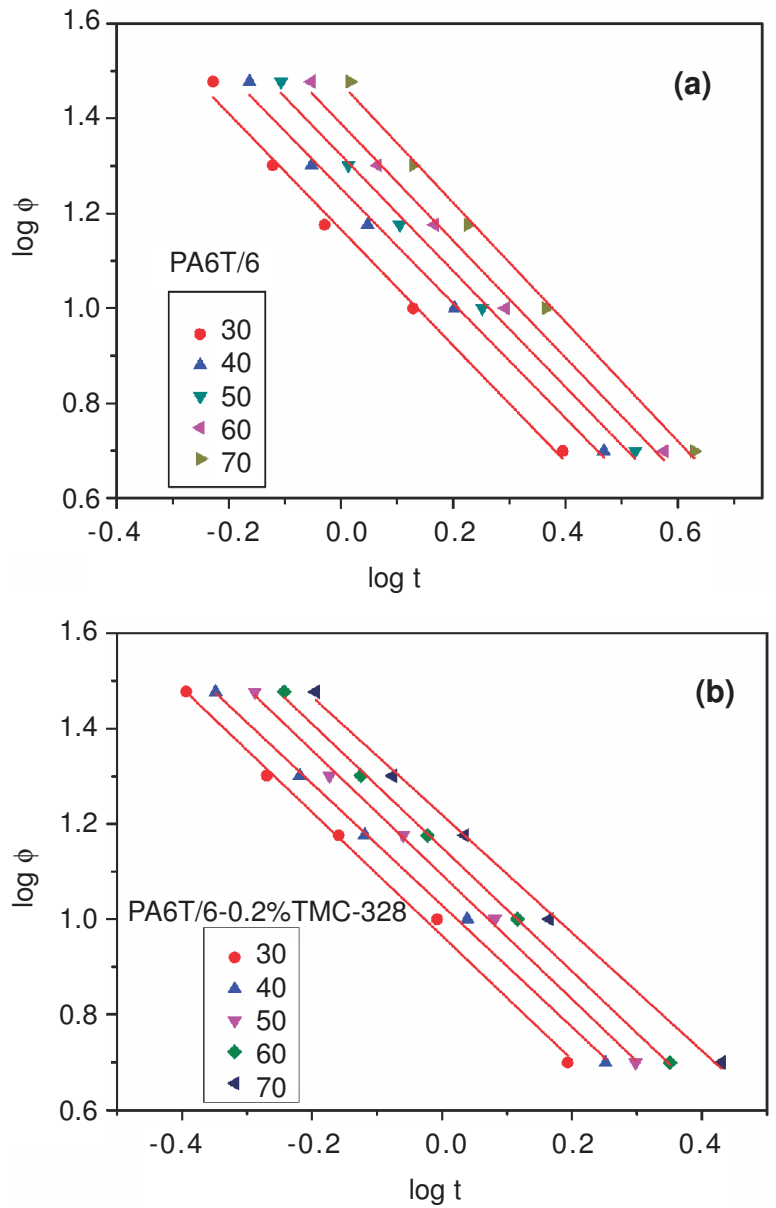

Fig. 5. $\log \phi$ versus $\log t$ for neat PA6T/6 (a) and PA6T/6-0.2 wt \% TMC5 composites (b) from the combined Avrami and Ozawa equation

\begin{tabular}{ccccccc}
\multicolumn{7}{c}{ TABLE-3 } \\
VALUES OF F(T) AND $\alpha$ VERSUS. \\
DEGREE OF CRYSTALLINITY FOR PA6T/6 \\
AND NUCLEATED PA6T/6 WITH TMC \\
\hline $\mathrm{X}(\mathrm{t})(\%)$ & & 30 & 40 & 50 & 60 & 70 \\
\hline \multirow{2}{*}{$\mathrm{PA6T/6}$} & $\mathrm{F}(\mathrm{T})$ & 14.62 & 17.86 & 21.03 & 24.43 & 29.71 \\
& $\alpha$ & 1.22 & 1.21 & 1.22 & 1.23 & 1.25 \\
\hline PA6T/6-0.2 wt & $\mathrm{F}(\mathrm{T})$ & 9.23 & 10.69 & 12.39 & 14.16 & 16.56 \\
\% TMC & $\alpha$ & 1.29 & 1.28 & 1.30 & 1.29 & 1.24 \\
\hline
\end{tabular}

to those obtained in the analysis on $\mathrm{t}_{1 / 2}$ and $\mathrm{Z}_{\mathrm{c}}$. These results indicate that the crystallization rate of PA6T/6 nucleated with TMC-328 is higher than that of PA6T/6.

Crystallization activation energy: Detailed kinetic analysis can give more information about the thermal transition inside the polymer materials. The Kissinger method ${ }^{13}$ is one of the most commonly used methods, through which the activation energy of the non-isothermal crystallization process can be easily obtained. The basic form of the Kissinger equation is shown in eqn. 5, where $\Phi$ is the cooling rate, $T_{p}$ is the peak temperature, $\Delta \mathrm{E}$ is the activation energy and $\mathrm{R}$ is the gas constant.

$$
\frac{\mathrm{d}\left[\ln \left(\Phi / \mathrm{T}_{\mathrm{p}}{ }^{2}\right)\right]}{\mathrm{d}\left[\ln \left(1 / \mathrm{T}_{\mathrm{p}}\right)\right]}=-\frac{\Delta \mathrm{E}}{\mathrm{RT}_{\mathrm{P}}}
$$

Then the activation energy can be calculated from the slopes of plots of $\ln \left(\Phi / \mathrm{T}_{\mathrm{p}}{ }^{2}\right)$ versus $1 / \mathrm{T}_{\mathrm{p}}$ (Fig. 6) by using the relation, $\Delta \mathrm{E}=\mathrm{R} \times$ slope. The $\Delta \mathrm{E}$ values of neat $\mathrm{PA} 6 \mathrm{~T} / 6$ and 
PA6T/6 lled with $0.2 \mathrm{wt} \%$ TMC-328 nucleating agent are -178.5 and $-250.8 \mathrm{~kJ} \mathrm{~mol}^{-1}$, respectively. $\Delta \mathrm{E}$ is negative due to exothermic nature of the transition from melt to crystalline state and negative activation energy values also imply that crystallization mechanisms are accelerated by decreasing the temperatures. Negative activation energy values have been reported for non-isothermal crystallization of $\mathrm{PBT}^{12}$ and $\mathrm{PET}^{14}$ composite systems. From the data it is obvious that the presence of TMC-328 causes significant changes in the value of activation energy in the PA6T/6. It is also found that $\Delta \mathrm{E}$ value of PA6T/6-TMC-328 is lower than PA6T/6 which refers to TMC-328 act as nucleating agents by lowering the crystallization activation energy. It is apparent that TMC-328(adn accelerate the crystallization of PA6T/6.

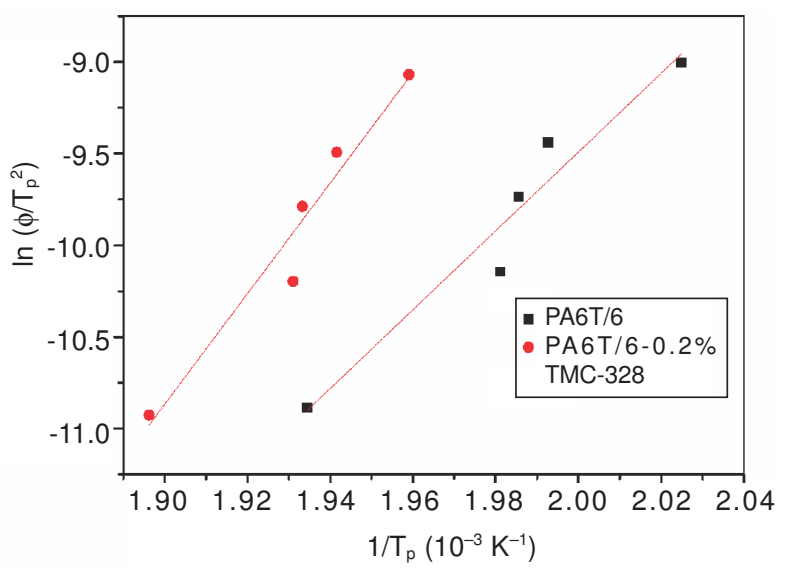

Fig. 6. Plots of $\ln \left(\phi / T_{\mathrm{p}}{ }^{2}\right)$ vs. $1 / \mathrm{T}_{\mathrm{p}}$ for samples crystallized non-isothermal

\section{Conclusion}

Non-isothermal crystallization kinetics and crystallization activation energies of PA6T/6 nucleated with multi amide compound nucleating Agent TMC-328 are compared with those of neat PA6T/6. The crystallization temperature of PA6T/6 increases and the crystal form of PA6T/6 is inuenced when
TMC-328 is added as nucleating agent, the crystallization rate of PA6T/6 nucleated with TMC-328 nucleating agent is higher than that of pure PA6T/6. The crystallization activation energy of PA6T/6 nucleated with TMC-328 is lower than that of neat PA6T/6. The TMC-328 nucleating agent exhibits higher efficiency for PA6T/6 crystallization.

\section{ACKNOWLEDGEMENTS}

The work was supported by Natural Science Foundation of Jiangsu, China (No. BK2011372), Natural Science Foundation of Jiangsu Province Colleges and Universities, China, (No. 11KJB430008) and Science Foundation of Nanjing Institute of Technology (YKJ201202).

\section{REFERENCES}

1. U. Koichi, K. Hirofumi, Y. Takashi and Y. Hiroki, EP Patent, 1860134A1, Europe (2007).

2. A. Siciliano, D. Severgnini, A. Seves, T. Pedrelli and L. Vicini, J. Appl. Polym. Sci., 60, 1757 (1996).

3. O. Persyn, V. Miri, J.M. Lefebvre, V. Ferreiro, T. Brink and A. Stroeks, J. Appl. Polym. Sci., B Polym. Phys., 44, 1690 (2006).

4. A.J. Uddin, Y. Ohkoshi, Y. Gotoh, M. Nagura and T. Hara, J. Appl. Polym. Sci., B Polym. Phys., 41, 2878 (2003).

5. A.J. Uddin, Y. Ohkoshi, Y. Gotoh, M. Nagura, R. Endo and T. Hara, J. Appl. Polym. Sci., B Polym. Phys., 42, 433 (2004).

6. A.J. Uddin, Y. Gotoh, Y. Ohkoshi, M. Nagura, R. Endo and T. Hara, J. Appl. Polym. Sci., B Polym. Phys., 43, 1640 (2005).

7. P. Pan, J. Yang, G. Shan, Y. Bao, Z. Weng and Y. Inoue, Macromol. Mater. Eng., 297, 670 (2012).

8. Z. Gui, C. Lu and S. Cheng, Polym. Test., 32, 15 (2013).

9. B. Han, N.Z. Fang, S.C. Zhang, C.X. Zhang, H.B. Wang and Q.M. Bie, Eng. Plast. Appl., 40, 12 (2012).

10. C.R. Herrero and J.L. Acosta, Polym. J., 26, 786 (1994).

11. A. Jeziorny, Polymer, 19, 1142 (1978).

12. A. Al-Mulla, J. Mathew, S.K. Yeh and R. Gupta, Composties A, 39, 204 (2008)

13. H. Kissinger, J. Res. Nat'l Bureau Stand, 57, 217 (1956).

14. W. Hao, X. Wang, W. Yang and K. Zheng, Polym. Test., 31, 110 (2012).

15. T. Liu, Z. Mo, S. Wang and H. Zhang, Polym. Eng. Sci., 37.3, 568 (1997). 